\title{
SMART MATERIALS TO ENHANCE THE BUILDING REACTION TOWARD THE UNDESIRABLE ENVIRONMENTAL CONDITIONS
}

\author{
S.H.ELDAKDOKY ${ }^{1}$ \\ Scometd@yahoo.com
}

\begin{abstract}
Air pollution, glare, solar radiation and heat gain are undesirable environmental conditions that negatively affect human health, building performance and energy consumption as well. Due to their extraordinary benefits, the Smart materials are globally developed and applied at various fields, particularly at architecture. This paper discusses the effect of incorporating the propertychanging smart materials within building envelope on enhancing building reactions and energy consumption as well. In this work, the smart materials were firstly defined; then, propertychanging smart materials that are able to enhance building reactions toward the undesirable environmental conditions were categorized to: phase-change materials for regulating the temperature, adhesion-changing materials for purifying the air and color-changing materials for controlling the temperature and natural lighting. These categories analyzed based on the type of influential stimulus on each category, the material reaction towards the surrounding environment, the function effect of the material, the available products as well as examples of the practical applications for each category. The study outcomes demonstrated that embedding property-changing smart materials within building envelope is able to achieve thermal and visual comfort, health care and energy saving as well, and they present a feasible substitute for conventional materials.
\end{abstract}

KEYWORDS: Stimulus; Property-Changing Smart Materials; Energy Consumption; Thermal Comfort; Building envelope.

\section{INTRODUCTION}

New materials Technology in the recent time plays an important role toward reducing the environmental pollution, solar radiation, heat gain and energy consumption within buildings. Those materials have been known since 1960 when scientists have found that Nitinol ( $\mathrm{Ni}-\mathrm{Ti}$ ) alloy has been able to get back its original shape under high temperature [1]. Since 1992, the conventional definition for construction and finishing materials all over the world has changed, where smart materials became the contemporary expression for the materials that have sensing reaction toward surrounding environment such as Piezoelectric materials and Adhesion-changing materials [2]. In the late of $20^{\text {th }}$ century, material properties have been developed for satisfying the global Contemporary needs and known as Smart and Nano materials, e.g. photochromic materials, matterexchanging smart materials, [3]; though their availability and costs are still hindering substituting them with conventional materials [2]. This innovative technique has recently attracted many researchers in this field; for example, Socaciu [4] studied the effect of usage phase change materials (PCMs) on buildings regarding to the energy saving and indoor thermal comfort; the author demonstrated that usage PCM for achieving the thermal optimization within buildings depends mainly on PCM type, its position in the

\footnotetext{
${ }^{1}$ Lecturer in Faculty of Engineering, Matria , Helwan University
} 
building, the percentage of PCM mixed with traditional material and the climatic conditions. Daveiga and Ferreira [1] explained and analyzed Smart and Nano Materials and their potential effect on architecture; the authors that are an architect and a materials scientist, started their work with a query about the usage of Smart and Nano materials in future architectural designs, and clarified that Smart and Nano Materials are looks like living organisms. The work concluded that creating the new buildings will be closer to the advanced systems, where the building elements will have functioning nature dependent on more than mere aesthetic purpose.

The smart materials are almost ignored in local business market where conventional materials are the predominant, though they are currently needed especially with the increasing of energy demands, air pollutants and global warming. Thus this work highlights how the integrating of property-changing smart materials into building envelope will enhance the building reaction toward the undesirable environmental conditions and energy saving as well.

\subsection{Objective}

The current research aims to investigate the effect of integration the propertychanging smart materials into building envelope on enhancing the building reactions toward the undesirable environmental conditions. In order to achieve the health care, thermal and visual comfort, as well as the energy saving.

\section{METHODOLOGY}

To achieve the objectives of this work, smart materials have been firstly defined. Then as summarized in (Figure 1), the property-changing smart materials that have influencing building reactions toward undesirable environmental conditions have been investigated and categorized into three types; phase-changing materials for regulating the temperature, adhesion-changing materials for purifying the air and color-changing materials for controlling the temperature and natural lighting. Each category has been analyzed regarding the influential stimuli, materials reactions and functions; in addition the available products and applied examples of each category have been presented. Finally, the analysis results have been discussed to specify the enhancements occurring due to incorporation of those various categories into building envelope. 
Figure (1) the methodology

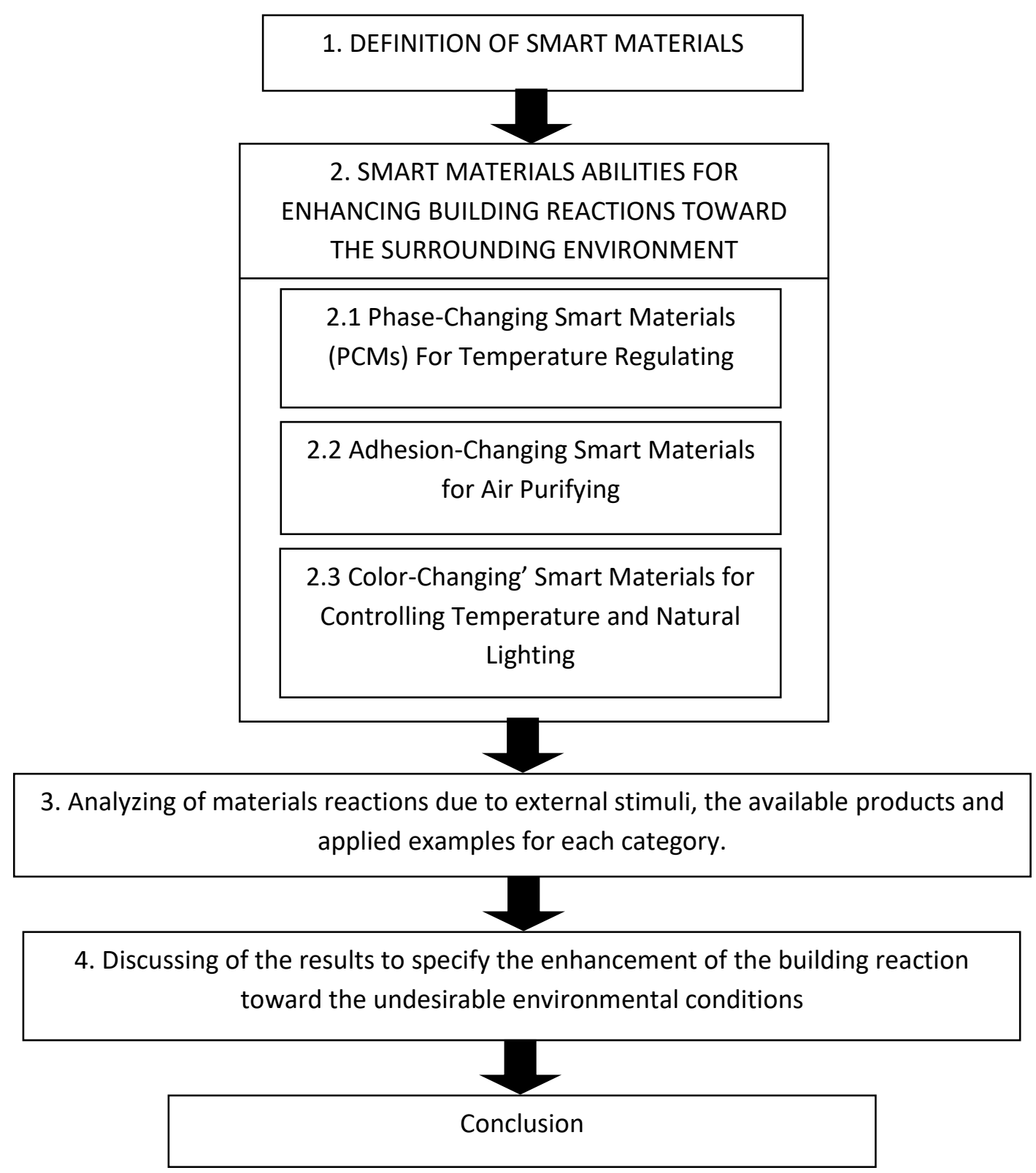

\section{DEFINITION OF SMART MATERIALS}

Smart materials receive an external stimulus and react by producing a valuable effect that may contain a signal that the materials are acting accordingly; they consider the answer for the recent technological needs [5]. Smart materials have several definitions, according to Addington, M. and Schodek, D "NASA defines smart materials as 'materials that "remember" configurations and can conform to them when given a specific stimulus .... A more sweeping definition comes from the Encyclopedia of Chemical Technology: 'smart materials and structures are those objects that sense environmental events, process that sensory information, and then act on the environment" [2].The common definition is the materials that have abilities to Sense the external stimulus such as temperature, light, electrical or magnetic field...etc then actuate accordingly and vice 
versa. Generally, smart materials are divided into property-changing smart materials and energy-exchange materials [2].

\section{SMART MATERIALS ABILITIES FOR ENHANCING BUILDING REACTIONS TOWARD THE SURROUNDING ENVIRONMENT [6] [3]}

The smart materials that are able to acclimatization the building towards thermal comfort, health as well as energy conservation [6] are divided into three categories as the following

\subsection{Phase-Changing Smart Materials (PCMs) For Temperature Regulating [1] [2]}

Materials included in this category are able to absorb and release the energy in form of light, heat, electric charges or hydrogen due to their chemical components; Consequently, their phases are usually changing from solid to liquid and vice versa[3] [4]. The most widely used materials are those which able to conserve and emit heat energy as shown in (Figure 2) for enhancing the thermal environmental conditions within buildings. The stored cold or heat is involuntarily emitted when surrounding temperatures fall or rise beyond the melting point of PCM; in summer for example, once the space temperature rises to above melting point of $P C M$, the extra heat will be absorbed and stored into the PCM so the space temperature will not increase further [7]. PCMs that are able to change their phases at temperature close to human thermal comfort $\left(20-28^{\circ} \mathrm{C}\right)$ can only be used in architectural field as indicated on (Figure 3) [4], because embedding PCMs in building elements can reduce the difference in temperature between daytime and nighttime similar to the effect of ancient thick stone walls [8].

Figure (2) Molecules phase changing due to temperature changing [2]

a. Crystaline phase

b. Intermediate phase

c. Amorphous phase
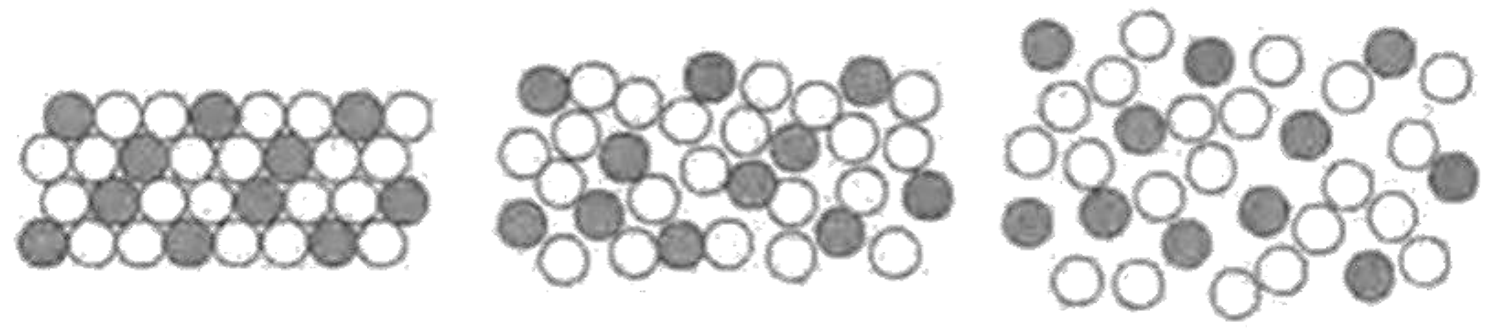

Figure (3) PCM Optimized room temperature [7]

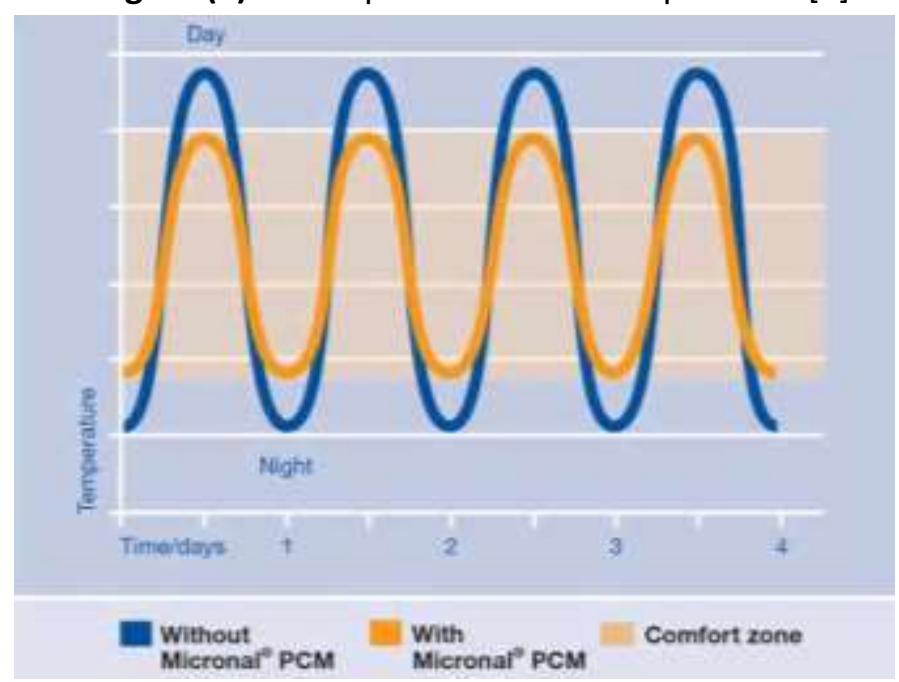


These materials can be organic such as paraffin wax, inorganic such as hydrated salt or organic-inorganic such as paraffin-salt hydrate mixtures [3]; unlike inorganic type, the organic type is flammable and has lesser density. In order to improve the relatively low thermal conductivity to PCMs, they are produced in form of micro capsules (2-20um), macro capsules or mixture with high conductivity materials. Anyway, they can be applied in buildings as a passive system and/or an active system. The most popular type is the passive system that results from integrating the PCM as an active ingredient into one or more of building elements such as walls, ceilings and/or floors, whereas the active system results from using the PCM in a separate store to be utilized only on demand [4]. The expected life time of the PCMs is 30years with full efficiency [8]. Correspondingly, PCMs effectively decrease the energy consumption for heating and cooling; for example, using $120 \mathrm{~m}^{2}$ of approx. of $360 \mathrm{~kg}$ PCM in a family house as shown in (Figure 4) will save the required energy for air-conditioning solution, the initial cost of this proposal will be retrieved within 5 years due to save the cost of both air condition installation and operation [7], in addition, integrating PCM into a residential house envelope $\left(100 \mathrm{~m}^{2}\right.$ floor area) will reduce approx $68 \%$ of the total energy required for heating [8].

Figure (4) Diagram shows how the PCM reduce the energy consumption of conventional air-conditioning [7]

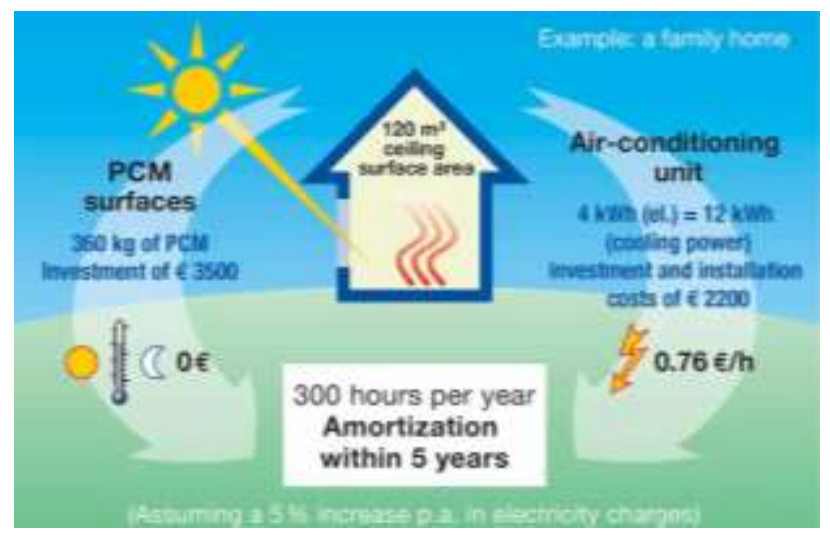

PCMs products are available in form of [3] [7]:-

- Powder form consisting of microcapsules for different construction purposes such as plaster for internal walls and ceiling.

- $\quad 2 \times 1.25 \times .015 \mathrm{~m}$ gypsum plasterboards.

- Insulating glass system consisting of four layers of glass confining three spaces; the internal space filled with hydrated salt whereas the external space containing lightdirecting prismatic panels as indicated on (Figure 5).

- Aluminum foil bags filled with hydrated salt or hydrated salt mixtures. 
Figure (5) Insulating glass system [3]

a. insulating glass system

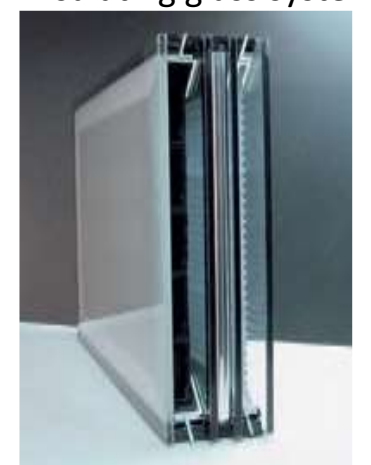

b. In summer

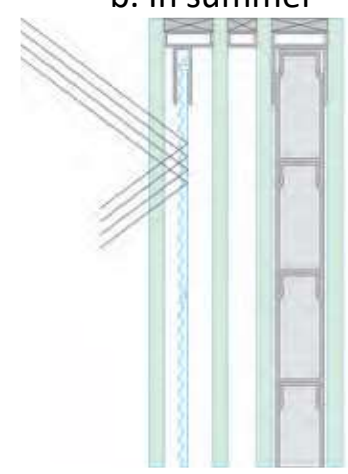

c. In Winter

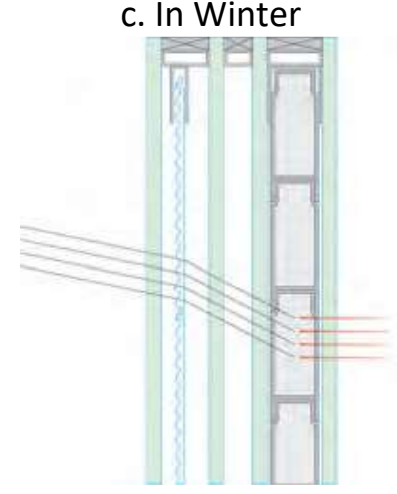

South façade of apartment building in Switzerland, 2004 [3] is an example for using insulating glass system as shown in (Figure 6), the façade area is of $148 \mathrm{~m}^{2}$ glass panels filled with a salt hydrate as PCM (total thickness of the panel $7.8 \mathrm{~cm}$ ). In summer, the prismatic panels in the external layer of panes reflect sun rays; in winter, low angel sun rays passing through panels are absorbed in form of thermal energy by hydrated salt in the internal layer of panes. When the temperatures of internal space fall beyond $26^{\circ} \mathrm{C}$, the absorbed heat will be released due to crystallization of the melted hydrated salt. This cycle of crystallization and melting is reflected on appearance of panes color from opaque to transparent and vice versa.

Figure (6) South façade of the apartment building- Switzerland [3]

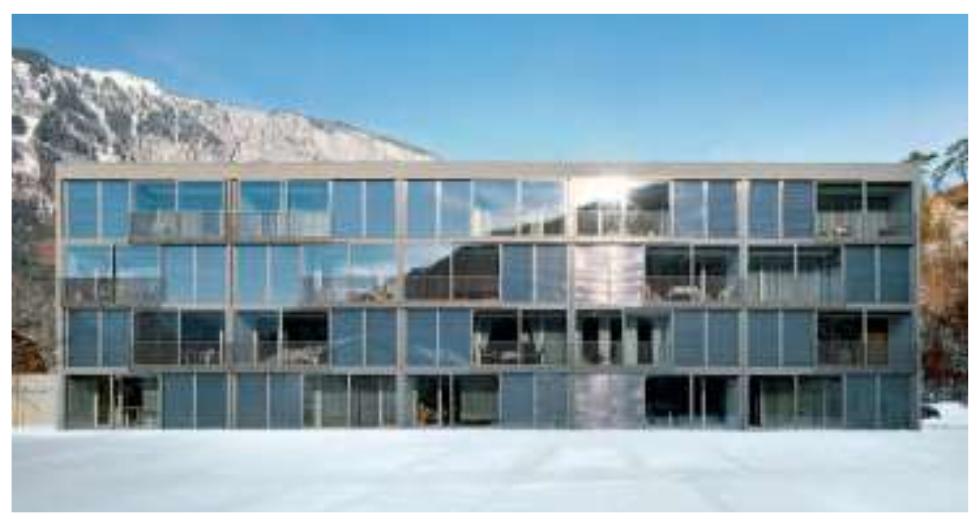

Contemporary House, Munich, 2005 [7] is another example of using $600 \mathrm{~m}^{2}$ of PCM lightweight board $(2 \times 1.25 \times 0.015 \mathrm{~m})$ in Contemporary House. This panel consists of Glass fiber nonwoven-covered gypsum wallboard with $P C M$, salt hydrate $/ 3 \mathrm{~kg} / \mathrm{m}^{2}$, in the gypsum core. The panel is classified as flame-retardant material, its Latent heat capacity is $330 \mathrm{~kJ} / \mathrm{m}^{2}$, and it is used for controlling the thermal environment within building as shown in (Figure 7). 
Figure (7) Internal view of Contemporary House, Munich [7]

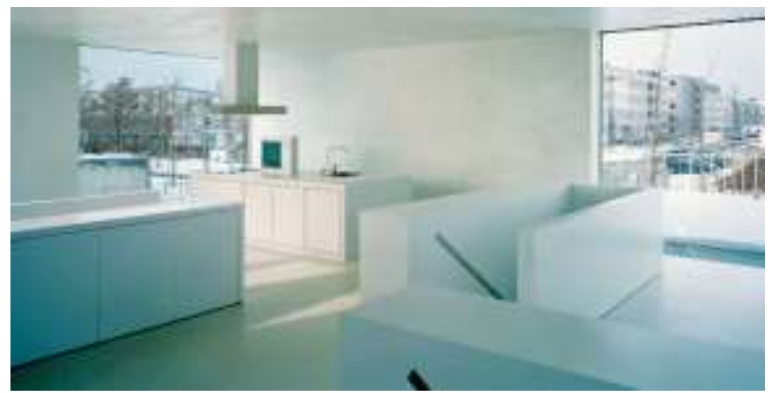

\subsection{Adhesion-Changing Smart Materials for Air Purifying}

This category of materials is able to enhance the quality of air and personal hygiene [8], the adhesion state of their atoms or molecules are changing due to external stimulus such as light, temperature, biological components or electrical field [3]. The available architectural materials are the photo-adhesive and hydro-adhesive smart materials that are able to purify organic pollution in air and water, in addition to self cleaning effect. A photocatalytic effect is resulting from biocide substance that primarily utilized $\mathrm{Ag}$ (Silver) particles and later $\mathrm{TiO}_{2}$ particles [8]. Titanium dioxide $\left(\mathrm{TiO}_{2}\right)$ is an organic solvent that has a photocatalytic effect and uses in wide range of successful applications especially in Japan and Germany [3], such as Photocatalytic cement resulted from adding $\mathrm{TiO}_{2}$ particles to cementitious material [9]. Photocatalytic and self-cleaning process as indicated on (Figure 8) take-place under the effect of solar radiation and in presence of water vapor or water. Firstly, $\mathrm{TiO}_{2}$ particles emit electrons that react with Oxygen $\left(\mathrm{O}_{2}\right)$ and produce super-oxide ions $\left(\mathrm{O}_{2}{ }^{-}\right)$, the resulted positive holes in the material surface react with $\mathrm{H}_{2} \mathrm{O}$ and produce hydroxyl radicals $(\mathrm{OH}-)$ ions. Secondly, the producing ions undergo secondary reactions to oxidize the organic substances and Bactria into harmless substances such as carbon dioxide and water molecules [3] [8]. Additionally, the negative $\mathrm{OH}$ - ions strongly bond with $\mathrm{TiO}_{2}$ surface due to its positive charges, and sequent layers of $\mathrm{H}_{2} \mathrm{O}$ blend with the previous layer in very low contact angle as shown in (Figure 9) [3] thus any dirt on the material surface be removed [3].

Figure (8) Diagram for photocatalytic effect of $\mathrm{TiO}_{2}$ surface in presence of solar radiation, the producing electrons transit from valence bond to conduction bond and decomposing organic molecules in air [8]

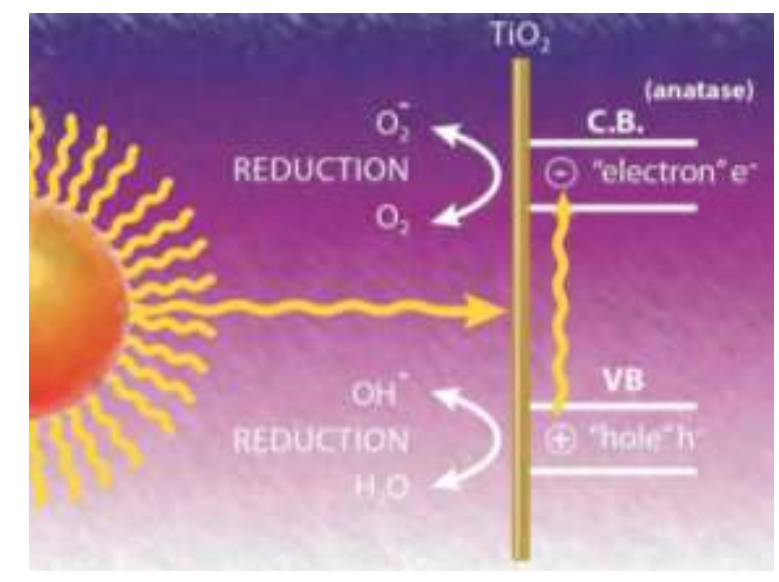


Figure (9) Hydrophilic surfaces of adhesion-changing smart materials [3]
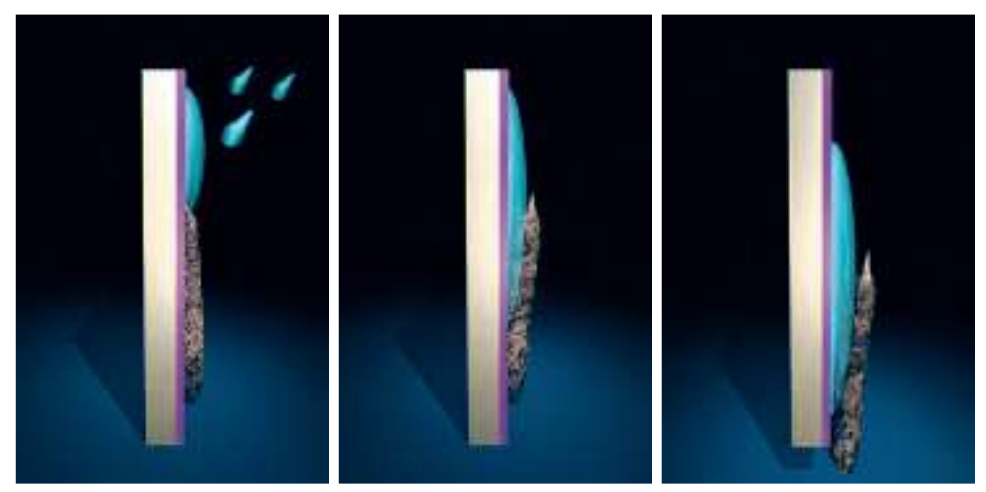

PCMs products are available in form of: photocatalytic paper as wall paper that interacts with UV light to oxidize organic polluted air molecules but it does not have self cleaning effect due to hygroscopic cellulose in paper, wall and floor ceramic tiles, glass panes, concrete pavement blocks, photocatalytic cement and textile membranes.

Garden chapel with Photocatalytic -Japan, 2001 is an applied example for usage of Photocatalytic product; this chapel is located in the garden of luxury hotel in Osaka, it consists of $50 \mathrm{~m}^{2}$ white membrane treated with $\mathrm{TiO}_{2}$ formed as two way curved shape supported on four points as shown in (Figure 10).

Monte Verde apartment tower - Austria, 2004 is another example for usage of Photocatalytic product. This high rise apartment tower is located in south Vienna, its facades is treated with self cleaning photocatalytic ceramic as shown in (Figure 11); the surfaces of the ceramic cladding are able to purify air and remove dust as well.

Figure (10) Self-cleaning chapel, Japan [3]

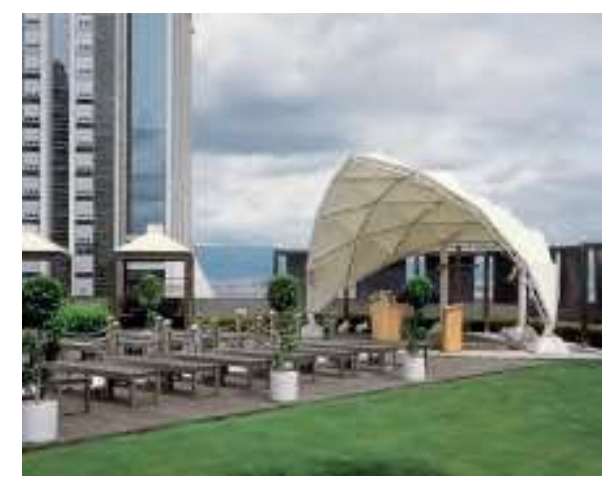

Figure (11).Self-cleaning façade of the apartment tower, Vienna[3]

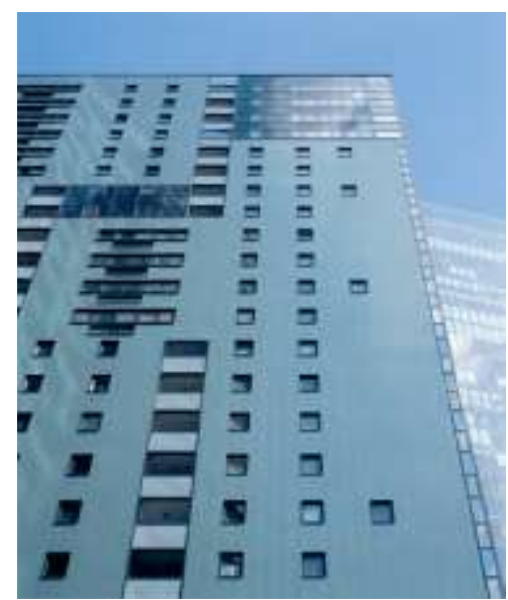

\subsection{Chromic or 'Color-Changing' Smart Materials For Controlling Temperature and Natural Lighting}

The molecular structure of these materials is changing due to external stimulus such as temperature, light, chemical, current or mechanical force, and its optical appearance is changing accordingly. These materials are usually used for controlling flow of light and 
heat through building envelope [10] so they decrease the potential energy consumption. The common architectural application is the switchable glazing technique (up to $1.2 \times 3 \mathrm{~m}$ ) that changes glass color from clearness to darkness/Opaque due to external stimulus, and vice versa. There are many types of switchable glazing as the following:-

\subsubsection{Reversible Thermotropic type}

This type depends on the passive technology, such as thermo-chromic glass that change its color as well as its thermal conductivity due to environmental temperature changing and vice versa[10]. The transition temperature does not correspond with the range of human thermal comfort, so this type is not suitable for architectural applications.

\subsubsection{Reversible Gasotropic type[10]}

This type consists of two panes trapped cavity filled with gas, its optical properties changes from clear to color within $20 \mathrm{sec}$ due to chemical reaction. It is not commercially available due to the difficulty of the gas injection system as well as the water vapor formed in case the hydrogen atoms are included in the chemical process.

\subsubsection{Reversible Electrotropic type}

This type includes three different devices of electrically activated glass; they require relatively low electrical power $\left(5 \mathrm{~W} / \mathrm{m}^{2}\right)$ for activation [10]. These types are as the following:-

- Glass panel with Suspended particle device (SPD) [2]: it consists of two transparent conducted layers trapped a liquid mixed with suspended particles, color change material, this group is inserted between two glass layers as indicated in (Figure 12). With no electric current, the particles will be arranged randomly and light will be blocked(Figure 12-b); with the electric current, the suspended particles will arranged regularly and light will pass through(Figure 12-a). For example, (SPD) smart glass of the external façade in the Daybreak studio, London, as indicated on (Figure 13), is used for controlling transition of UV, glare and heat [11].

Figure (12) suspended particle type(SPD) [2]

a. Clear color when electric current is turned on

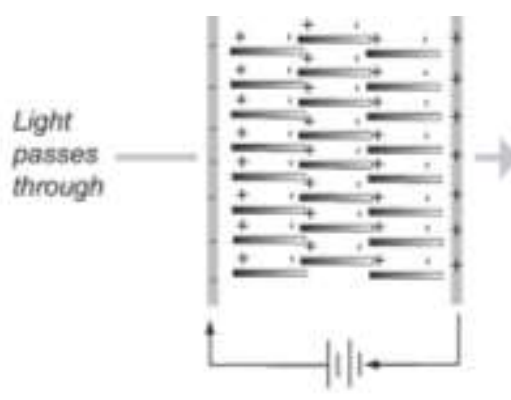

b. Dark color when electric current is turned off

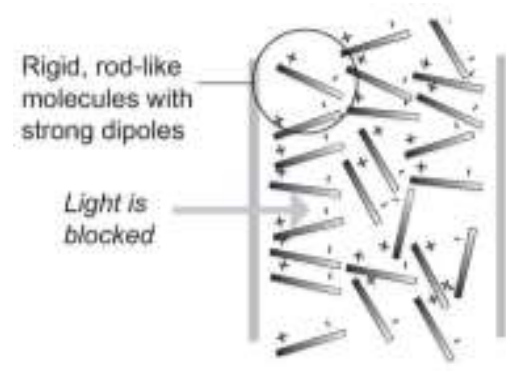


Figure (13) Smart Glass façade of Daybreak studio, London [11]

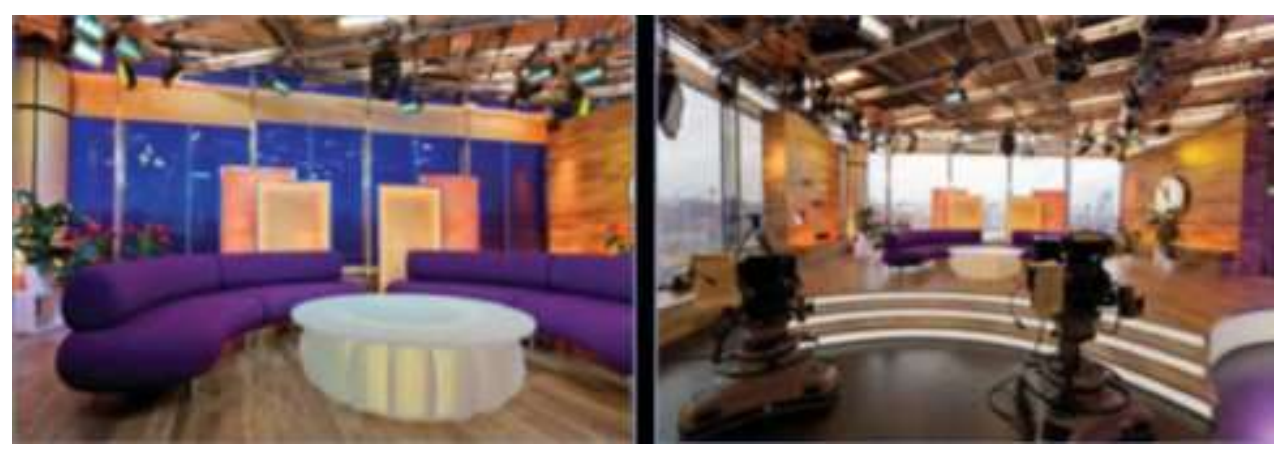

- Polymer-dispersed liquid crystals glazing (PDLC)[2]: it consists of two glass layers surrounding a two layers of synthetic plastic sheet (used as polarizing filter ${ }^{2}$ ) that trapped liquid crystals. With no electric current, the crystal chains will randomly arrange and it will screw path of the polarized light, so the filter will transmit light and glass will be transparent as shown in (Figure 14-a). With the electric current, the crystal chains will align without affecting the polarized light path, so the polarizing filter will block light and glass will be opaque as shown in (Figure 14-b). PDLC that provides the privacy is not able to reduce the quantity of emitted solar radiation. For example, the PDLC smart glass panel of $3 \mathrm{~m}$ high for front entrance façade of the East Winter garden venue, Canary Wharf, London, it is used for controlling daylight transition in addition to achieve the privacy for particular receptions; when the current is turned on, the glass color changes to opaque and transmits only $67 \%$ of daylight as shown in (Figure 15 ).

Figure (14) Effect of liquid crystals [2]

a. second layer of filter transmit light when electric current is turned off

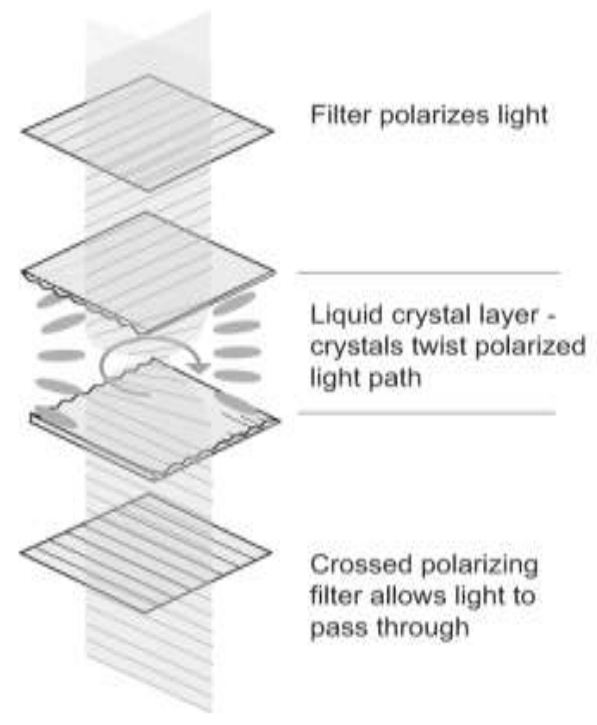

b. second layer of filter block light when electric current is turned on

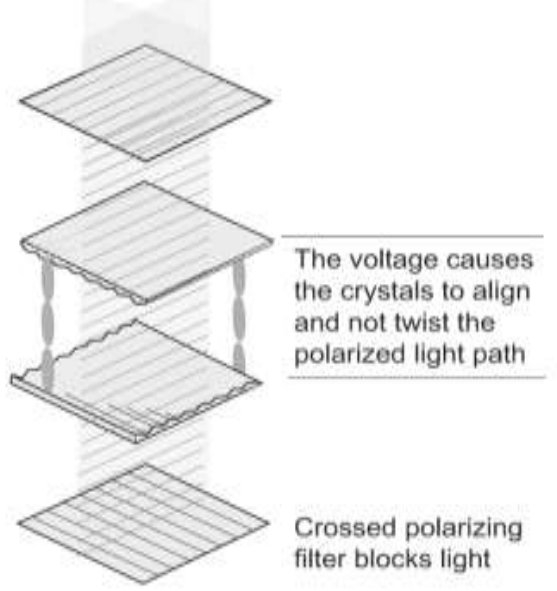

${ }^{2}$ This material is consisting of embedded microscopic crystals of iodoquinine sulfatein plastic film in order to block light which is gather parallel to the direction of the crystal alignment and transmits light which isgather perpendicular to it 
Figure (15) PDLC glass for the front elevation-East Wintergarden venue, London [11]
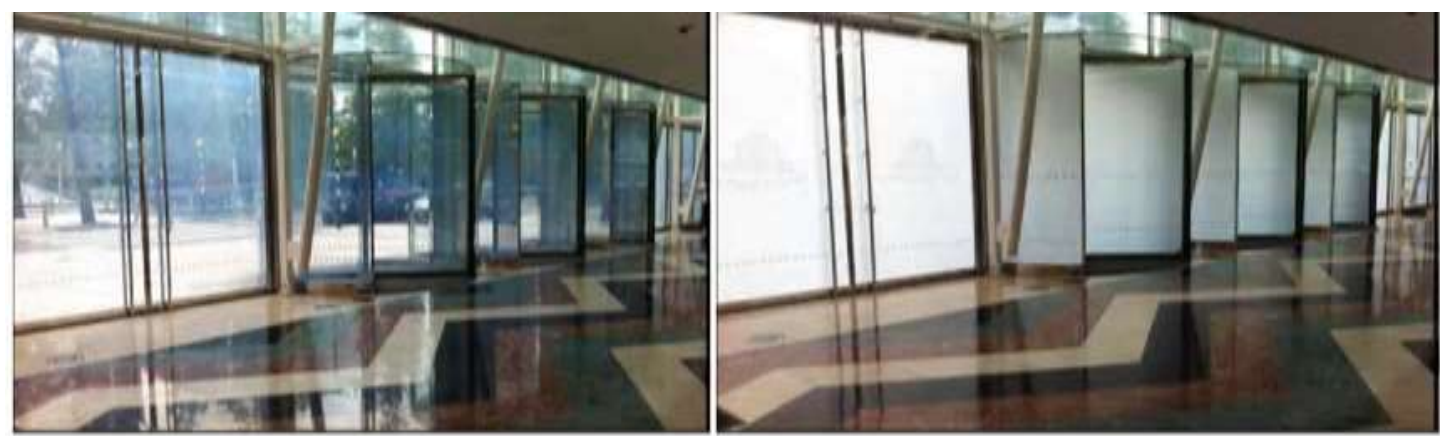

- Electrochromic glazing [2]: it consists of an ion conducted layer trapped between electrochromic layer (e.g. tungsten oxide $\mathrm{WO}_{3}$ ) and ions basin (hydrogen or lithium); this group are surrounded by two transparent conducted layers, and sandwiched between two layers of glass as indicated on (Figure 16). With the electric current, the ions will move through the ion conducted layer to electrochromic layer and will change its color to blue as shown in (Figures 16-a\& 17); with the inverse of the electric current, the ions will move from electrochromic layer to ion basin and electrochromic layer will change to clear(Figures 16-b\& 17) [2]. This type is able to control the quantity of solar radiation, where it life time is of 10-15years [10]. The main disadvantage of this type is the required continuous current as external stimulus [2], in addition its color reversing is relatively slower than other technologies, it takes approx. 30min for a glass size of about $2.4 \mathrm{~m}^{2}$ [10].

Figure (16) Electrochromic Glazing [2]

a. Dark state when electric current is turned on

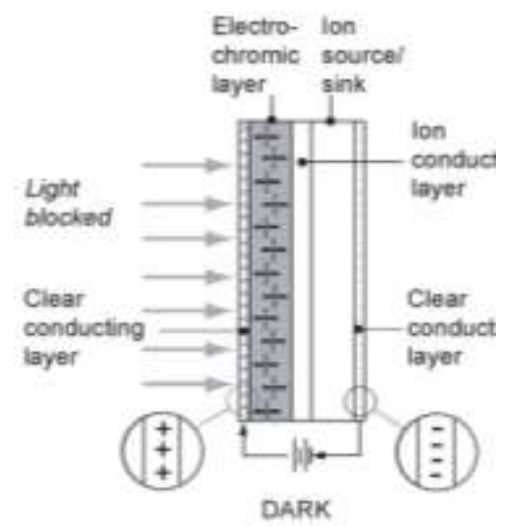

b. Clear state when reversing electric current

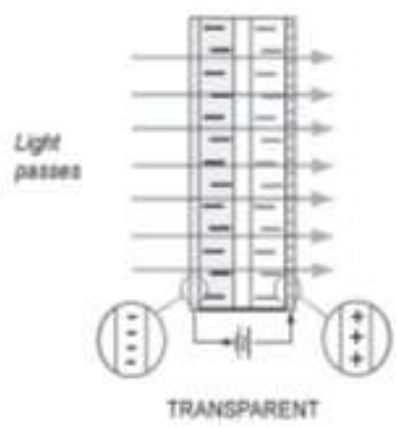


Figure (17) Electrochromic glazing in both cases [3]

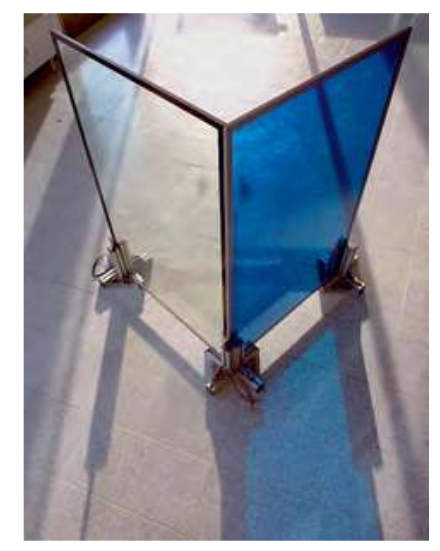

\section{DISCUSSION}

Although the recent era is escorted with unstable Earth's temperature, poor air quality and rising energy demands; it is also accompanied with new technologies that introduce effective solutions for mitigating those problems. In architecture, the innovative materials technology introduces unique solutions to enhance building reactions toward the surrounding environment. One of these solutions is the incorporating of the property-changing smart materials in the building envelope; this solution is effectively able to achieve the visual and thermal comfort, health care and energy saving within building. Generally, Smart materials are divided into two main types based on their reactions due to external stimuli: property-changing smart materials and energy-exchange materials [2]. Three different categories of the first type materials are able to enhance buildings reactions toward the undesirable environmental conditions. Those categories, as summarized in table1, are namely PCMs for regulating the temperature, Adhesion-Changing Smart Materials for purifying the air and ColorChanging Smart Materials for regulating temperature and natural lighting.

Table(1) Summary for the various categories of property-changing smart materials

\begin{tabular}{|l|l|l|l|}
\hline $\begin{array}{l}\text { Name of Smart } \\
\text { Material }\end{array}$ & $\begin{array}{l}\text { Phase-Changing } \\
\text { Materials (PCMs) }\end{array}$ & $\begin{array}{l}\text { Adhesion-Changing } \\
\text { Materials }\end{array}$ & $\begin{array}{l}\text { Color-Changing } \\
\text { Materials }\end{array}$ \\
\hline \hline Material function & $\begin{array}{l}\text { Temperature } \\
\text { Regulating }\end{array}$ & $\begin{array}{l}\text { Air Purifying and personal } \\
\text { hygiene }\end{array}$ & $\begin{array}{l}\text { controlling flow of } \\
\text { light and heat }\end{array}$ \\
\hline $\begin{array}{l}\text { Common external } \\
\text { stimulus }\end{array}$ & $\begin{array}{l}\text { Temperatures } \\
\text { changing }\end{array}$ & Light & Electric current \\
\hline Material reaction & $\begin{array}{l}\text { Absorbs, conserves } \\
\text { and emits heat energy }\end{array}$ & $\begin{array}{l}\text { Changes the adhesion state } \\
\text { of its atoms or molecules }\end{array}$ & $\begin{array}{l}\text { molecular structure } \\
\text { of the materials } \\
\text { changes }\end{array}$ \\
\hline Available products & $\begin{array}{l}\text { Powder - gypsum } \\
\text { plasterboards- } \\
\text { Insulating glass - } \\
\text { Aluminum foil bags }\end{array}$ & $\begin{array}{l}\text { wall paper - ceramic tiles- } \\
\text { glass panes- concrete } \\
\text { pavement blocks- } \\
\text { photocatalytic cement - } \\
\text { textile membranes }\end{array}$ & $\begin{array}{l}\text { Reversible glazing } \\
\text { system }\end{array}$ \\
\hline Applied example & $\begin{array}{l}\text {-South façade of an } \\
\text { apartment building, } \\
\text { Switzerland }\end{array}$ & $\begin{array}{l}\text {-Self-cleaning façade of an } \\
\text { apartments tower, Vienna }\end{array}$ & $\begin{array}{l}\text {-Smart Glass façade } \\
\text { of Daybreak studio, } \\
\text { London }\end{array}$ \\
\hline
\end{tabular}


PCMs are involuntarily able to regulate the indoor temperature of buildings to achieve the acceptable thermal comfort limits. Thus they reduce the required energy for heating and cooling; approximately $3 \mathrm{~kg}$ of $\mathrm{PCM} / \mathrm{m}^{2}$ of building envelope is suitable for maintaining the internal temperature within $21^{\circ} \mathrm{C}$ in hot climate [8]. In addition to self cleaning effect, the Adhesion-Changing Smart materials are able to purify the air; $1000 \mathrm{~m}^{2}$ of Photocatalytic material surface is able to clean the air pollution by about $200,000 \mathrm{~m}^{3}$ of air volume /day [9] that is equivalent to 70 flurried trees of average size [3]. Unlike the other two categories, Color-Changing Smart Materials require very low electric power, max.115 volts, to be stimulated [10]. Other than PDLC type that does not reduce the heat flow to building and does not save the cooling energy, SPD and Electrochromic glass reduce the solar radiation and reduce the buildings energy consumption accordingly, they are able to save of $35-60 \%$ of lighting energy and to partially reduce the annual cooling loads [10]; they also able to improve the occupants comfort by preventing glare, providing satisfactory level of natural light and privacy as well. For instance, SPD glass is able to block about $90 \%$ of the solar heat gain into buildings and save more than $45 \%$ of annual cooling energy [10].

In other words, embedding suitable products of the property-changing smart materials within building envelope will improve the building performance as the following:-

- Incorporating of PCM into external walls will present an efficient storage medium for thermal energy, thus it will maintain the internal temperature within thermal comfort limits and will reduce the required energy for heating or cooling as well. For example, Latent heat capacity for standard gypsum plaster board is $0 \mathrm{~kJ} / \mathrm{m}^{2}$, whereas it is 330 $\mathrm{kJ} / \mathrm{m}^{2}$ for PCM smart board [7].

- Treating the external surfaces of buildings with Adhesion-Changing Smart Material, e.g. photocatalytic ceramic tiles for wall and floor, concrete pavement blocks for sidewalks, and photocatalytic cement for plaster work, will reduce the air pollution by oxidizing the organic molecules.

- Usage of SPD or Electrochromic glass for external facades instead of the conventional types will significantly achieve visual comfort and privacy as well as reduce the energy consumption for lighting and cooling.

\section{CONCLUSIONS}

- Since Smart materials perform many functionalities due to their involuntary and reversible reactions towards external stimuli, they represent a feasible substitute for conventional materials to enhance the building performance and energy consumption.

- In order to maximize the potential benefits of smart materials applications as a fundamental element in the design; the architects should deeply understand their structures and properties, in addition to work together with material scientists to support the materials influence in the future of architecture.

- Usage of suitable products of the property-changing smart materials within building envelope will improve building reaction toward undesirable environmental conditions by reducing the internal heat gain and air pollution, providing self cleaning effect, visual comfort and privacy well as. 
- Building facades should be considered as a major element of low energy building; embedded property-changing smart materials in building envelope will save the energy of cooling, heating and lighting, and will simplify control systems of building.

- In addition to controlling of heat flow, smart glass is able to minimize glare, eliminate shades and blinds and protect furniture from fading.

- To encourage developers and architects for maximizing the benefits of building smartness, it is important to clarify how the smart materials reduce the energy consumption and benefit the occupants as well.

- Abilities of the innovative materials discussed in this work represent a small part of large varieties of other smart materials abilities for satisfying other requirements of today's architecture. In a sense, more future studies for their new possibilities in architecture are needed.

\section{REFERENCES}

1. Daveiga, J. and Ferreira, P., "Smart and Nano Materials in Architecture", ACADIA05, USA, V. 20, p.58-67, 2005.

2. Addington, M. and Schodek, D.," Smart Materials and new technologies", $1^{\text {st }}$ Edition, Elsevier's Science and Technology Department in Oxford, UK, 2005.

3. Ritter, A., "Smart Materials in architecture, interior architecture and design", English Edition, Birkhauser-publishers for architecture, Germany, 2007.

4. Socaciu, L.G.," Thermal Energy Storage with Phase Change Material", Leonardo Electronic Journal of Practices and Technologies, V. 20, p.75-98, 2012.

5. Sadeghi, M. J., Masudifar, P. and Faizi, F., "The Function of Smart Material's behavior in architecture", International Conference on Intelligent Building and Management, Singapore, vol.5, 2011.

6. Berge, B., "The Ecology of Building Materials", 2nd edition, Elsevier's Science and Technology Department in Oxford, UK, 2009.

7. Technical department of BASF, "Intelligent Temperature Management in an Extremely Lightweight Approach", BASF brochure", Germany, 2006.

8. Sánchez-Muñoz1, L., et al "research \& development for ceramic tiles" in the 21st century: competition, diversity, and functionality", Institute of ceramic, Spain and Inorganic and Organic Chemistry Dept, Spain, 2010.

9. Leone,M.F., "Nanotechnology for Architecture. Innovation and Eco-Efficiency of Nanostructured Cement-Based Materials", Architectural Engineering Technology, Leone, V. 1, 2012.

10. Beevor, M., "Smart Building Envelopes/ 4TH Year Project Report" University of Cambridge, Department of Engineering, UK, 2010.

11. Sadeghi,M.J., Masudifar., P., and Faizi.,F.," The Function of Smart Material's behavior in architecture", Vol.5, International Conference on Intelligent Building and Management, Singapore, 2011. 